hence the difference in the per cent. of potash on the two preparations.

Nos. 648 and 649 show quite similar results to No. 639 both in the percentages of fine soil passing the sieves and in the percentages of potash.

Nos. 750 to 844 inclusive are representative samples of the coarser soils of the Atlantic Coastal Plain. The differences in the percentages of soil passing the two sieves are very similar, all or practically all of the sample passing the $2 \mathrm{~mm}$. sieve and only from 59.6 to 88.5 per cent. passing the $0.5 \mathrm{~mm}$. sieve. The difference in the percentages of potash are also very similar, $i . e$, the per cent. being considerably lowered when more of the sample is analyzed on the $2 \mathrm{~mm}$. preparation than on the $0.5 \mathrm{~mm}$. The microscopic examination of the coarse particles from these samples showed them to be composed almost entirely of pure quartz.

From the table and microscopic examinations it will be seen that the greater portion of the plant food is found in the soil particles less than $0.5 \mathrm{~mm}$. in diameter, that is, the particles between 0.5 and $2 \mathrm{~mm}$. in diameter are composed chiefly of quartz, the exceptions to this being the samples in which there was only a slight difference in the analysis on the two preparations and the microscopic examination of the coarse particles showed them to contain considerable amounts of feldspar.

If we assume that the particles of soil less than $2 \mathrm{~mm}$. in diameter fairly represent what should be termed the soil from which the plant derives its food, it is evident that in making determinations of the total plant food, the analysis if made on a sample prepared through a sieve with perforations less than $2 \mathrm{~mm}$. in diameter, $i . e ., 0.5 \mathrm{~mm}$., will show the soil to contain considerably more plant food than the soil from which the plant must derive its food and hence does not fairly represent the composition of the soil.

North Carolina Department of Agriculture, Division OF CHEMISTRY.

\section{THE CHANGES IN CRUDE PETROLEUM EFFECTED BY DIFFUSION THROUGH CLAY.}

By Dayid T. Day and J. Elliott Gilpin. Received May 3, 1909.

That the process of diffusion through clay and shale and the replacement by water have been important factors in the concentration of petroleum in certain places was pointed out by Day in $1897^{1}$

Proc. Amer, Philos, Soc., Vol. XXXVI, No. 154. and is shown very clearly by recent work of Gilpin and Cram. ${ }^{1}$ Suppose, for example, the petroleum formed in the deeper portions of the earth finds access through a seam or other opening to a layer of fine-grained clay or shale. It will diffuse through the material if the latter is finely divided, but would be stopped by material too coarse for capillary diffusion. These authors have found that the oil will rise in tubes packed with fuller's earth and in so doing is partly fractionated. By using several tubes and uniting oils of the same specific gravity, oil of different grades can be collected in sufficient quantity to be fractionated again, and the process can be continued until oils are obtained which are not altered by further passage through tubes filled with fuller's earth.

If such a diffusion took place in a large mass of clay no accumulation of oil would be found at any one spot, and a well drilled in this material would show only a small percentage, say 5-10 per cent., of petroleum. If now, as has been shown by Gilpin and Cram, water, either surface or subterranean, comes in contact with this clay it will diffuse into it and displace $2 / 3-3 / 4$ and perhaps, in long geological periods, even more of the petroleum.

If the water surrounds the mass of clay the oil cannot escape and is driven finally into the coarse adjacent layers such as sandstone and gravel. The oil will remain in this position as it cannot be displaced by any capillary action of water on the rock.

The pressure under which it could accumulate would be entirely independent of hydrostatic pressure, and pressures equivalent to those observed in the phenomenon of osmosis can be brought about without an amount of water more than sufficient to saturate the clay itself--practically an infinitely smaller amount of water than is required for producing hydrostatic pressures equivalent to the pressures found in oil wells. These pressures are usually from 50 to $300 \mathrm{lbs}$. to the square inch-clearly within the range of osmotic pressure.

Pressures as high as $\mathrm{I} 500$ tbs. per square inch have been claimed for natural gas, but it is not to be supposed that all accumulations of oil and natural gas are attributable to the phenomena here under consideration. The various conditions of accumulation of petroleum, however, are so easily explained by the driving out of oil by water,

\footnotetext{
1 Amer. Chem. Jr., 40, 495.
} 
that it seems extremely probable that many petroleum accumulations are due to this action. The process by which these facts have been established is as follows: tin tubes 5 feet and I I/4 inches in diameter, closed at the bottom with corks along whose sides, grooves were cut to admit the oil, were packed with fuller's earth, the earth being introduced in small quantities at a time and packed by a ramrod before the next lot was added. These were then placed in vessels containing petroleum and the air in the tubes was removed by a suction pump to facilitate the diffusion. After the oil had nearly reached the top of the tubes the clay was removed in sections and treated with water to displace the oil.

If a little water is added to the earth as removed from the tubes, after standing a few minutes all the water will pass into the earth and this will be accompanied by the liberation of oil. Oil so liberated can then be poured off directly from the earth without the labor of churning. When water first begins to liberate oil, the earth is granular; but when more water has been added and the last of the oil recovered, the earth has the consistency of a thin paste that will flow when the dish is inclined, which it will not do when the oil begins to come off.

All the oil from one section of a tube is of the same color irrespective of whether it is the first or the last oil to come off when water is added. It was assumed at first that all the oil which came from one section of earth had the same specific gravity, but this was found later not to be the case. The first oil to be collected, if taken in sufficiently small volume, say about $20 \mathrm{cc}$., is slightly heavier than the next portion. If as much as Ioo cc. are included in the first sample, however, this will not be true. Beginning with the second sample the successive portions of oil steadily increase in specific gravity, the gradual addition of water affording another means of fractionation in addition to the separating power of the earth. Both of these methods of separation have been combined in this investigation. The earth must be thoroughly mixed after each addition of water to prevent a layer of water-wet earth from isolating earth that contains oil from the water added.

The petroleum used was a dark green oil from Venango County, Pa., of specific gravity o.8Io. When $950 \mathrm{cc}$. of this oil were drawn upward in a tin tube $5 \frac{1}{2}$ feet long, the following separation was obtained:

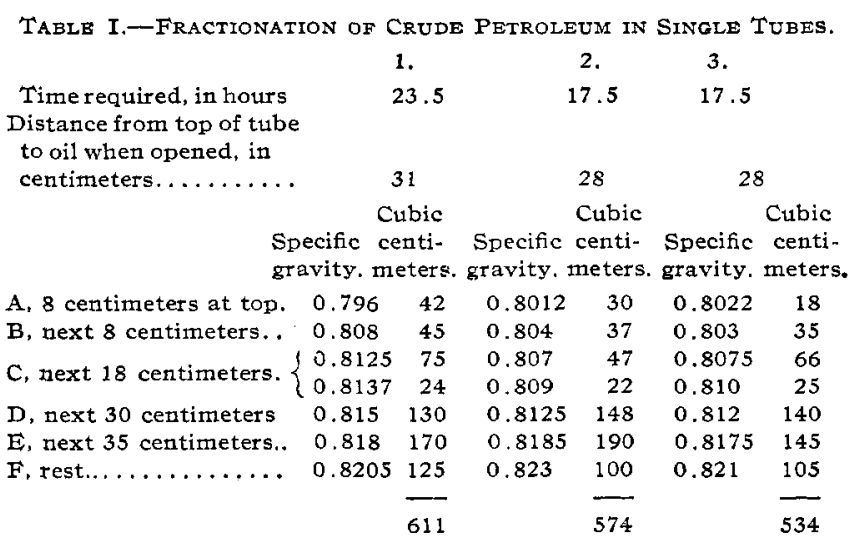

The oil in grade $\mathrm{C}$ was collected in two portions, the second being obtained by the addition of more water after the first lot of oil was poured off. A1though $950 \mathrm{cc}$. of crude petroleum were used in each experiment, it will be noticed that the oil recovered measures much less than that. When several tubes were worked up together, in one test 9,070 cc. of crude petroleum yielded 5,95 I cc. of oil and in another $8,915 \mathrm{cc}$. gave $5,415 \mathrm{cc}$.

That the addition of water in small portions acts as a fractionating agent in addition to the action of the clay is clear from a consideration of the following table:

When the first portion of oil was liberated, the mass was of the consistency of bran, but as more water was added it turned to a fluid paste. When water was added and the pail inclined, oil would continue to drain out for half an hour or longer before the addition of more water became necessary. The oil which was liberated by one lot of water, therefore, could be collected in several portions, and this was done to see whether the oil which comes off immediately after the addition of water is the same as that which drains out later. The letters I, II, etc., indicate that the fractions included were liberated by one addition of water.

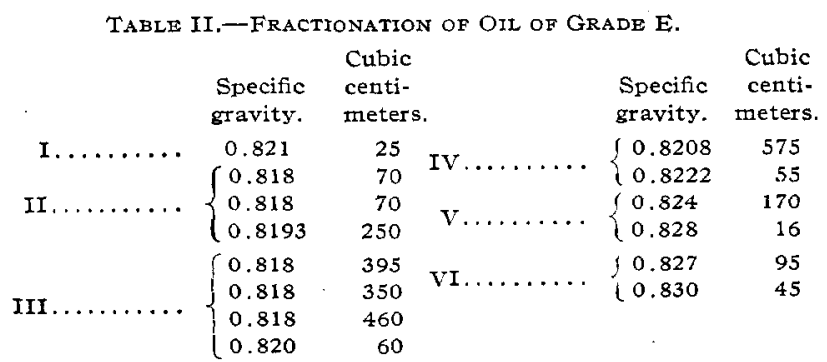

The first fraction is regularly of higher specific gravity than those immediately following if only enough water is added to liberate a first fraction of small volume, say about $20 \mathrm{cc}$. As the fraction 
first obtained becomes larger in volume, it approaches nearer to the second fraction in specific gravity, and will even fall below that fraction if the volume is made too large.

The range of specific gravity covered by this first fractionation of the crude petroleum of specific gravity 0.8 Io was from 0.800 to 0.830 . Fractions of the same specific gravity and of the same grade were united and the products chilled and filtered to remove all the dissolved paraffin possible. This was done out of doors toward the last of December, when the thermometer stood at about 4 to $8^{\circ} \mathrm{C}$. Lower temperatures would not only throw paraffin out of solution, but cause the whole oil to thicken. The oils were filtered through large plaited filters of drying paper, twenty-four hours or more being required for many of the filters to empty completely. The lighter oils in Sections $A$ and $B$ deposited no paraffin. Some of the heavier grades deposited as much as Io per cent. of their weight, accompanied in many cases by a slight change in specific gravity.

Oil of the same specific gravity was refractionated and the process continued up to the fourth generation. The oil obtained in this fractionation has the following specific gravities: colorless. On evaporation of the ether there remained about $8 \mathrm{cc}$. of a heavy oil with the color of the natural petroleum. Pressure, heat, and extraction with ether together gave about half the amount of oil which the earth must have contained.

Earth that had been used once was allowed to dry for several weeks at room temperature until it had lost all appearance of containing moisture. It was then pulverized, sifted, and 720 grams used in a tube with $740 \mathrm{cc}$. of the crude petroleum of specific gravity $0.8 \mathrm{I}$, with the following results:

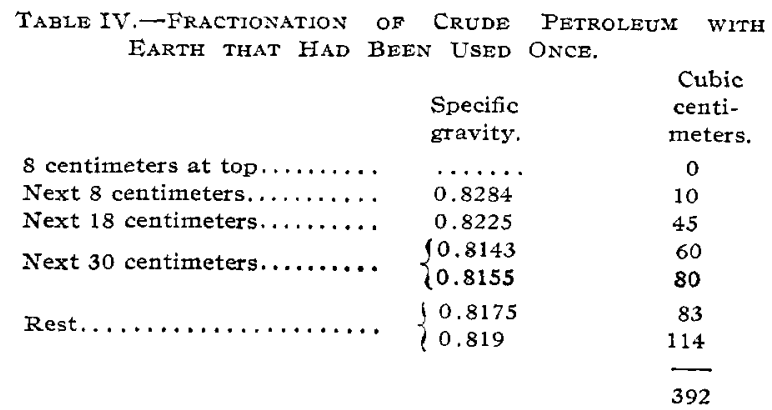

The first oil up the tube is evidently absorbed by heavy material in the earth; the first oil recovered dissolves material from the earth, which increases its specific gravity beyond that of the next fraction.

\begin{tabular}{|c|c|c|c|c|}
\hline & \multirow{2}{*}{\multicolumn{2}{|c|}{$(0.815)$}} & & FOURTE \\
\hline & & & \multicolumn{2}{|c|}{$(0.8168)$} \\
\hline & $\begin{array}{l}\text { Specific } \\
\text { gravity. }\end{array}$ & $\begin{array}{l}\text { Cubic. } \\
\text { centi- } \\
\text { meters. }\end{array}$ & $\begin{array}{l}\text { Specific } \\
\text { gravity. }\end{array}$ & $\begin{array}{l}\text { Cubic. } \\
\text { centi- } \\
\text { meters. }\end{array}$ \\
\hline A........... & 0.8135 & 19 & 0.812 & 30 \\
\hline B......... & 0.805 & 27 & 0.8122 & 42 \\
\hline & 0.8118 & 50 & 0.8165 & 55 \\
\hline c. & 0.813 & 15 & 0.818 & 25 \\
\hline$D \ldots \ldots \ldots \ldots$ & 0.8147 & 140 & 0.818 & 160 \\
\hline EF $\ldots \ldots \ldots$ & 0.8175 & 360 & 0.8195 & 305 \\
\hline & & 611 & & 617 \\
\hline
\end{tabular}

The sum of the fractions of oil displaced from the earth is as a rule only about $2 / 3$ of the volume of the oil used. A pressure of approximately 200 tons per square inch on the earth from which water has displaced all oil that it will result in the liberation of considerable water but very little oil. When earth which has been pressed is heated to $165^{\circ}$ for three hours, considerable water distils over, but much less oil than would be expected; for example, from 75 grams of earth which should contain $25 \mathrm{cc}$. of oil only $4 \mathrm{cc}$. of oil was obtained. The earth was removed once from the flask and pulverized, and when the heat was discontinued the earth was thoroughly dry. On extraction with ether in a Soxhlet extractor the earth gave a solution having the color of the original petroleum. The extraction was continued until the extract was

\begin{tabular}{|c|c|c|c|c|c|}
\hline \multicolumn{2}{|c|}{$(0.819)$} & \multicolumn{2}{|c|}{$(0.8205)$} & \multicolumn{2}{|c|}{$(0.823)$} \\
\hline $\begin{array}{l}\text { Specific } \\
\text { gravity. }\end{array}$ & $\begin{array}{l}\text { Cubic } \\
\text { centi- } \\
\text { meters. }\end{array}$ & $\begin{array}{l}\text { Specific } \\
\text { gravity. }\end{array}$ & $\begin{array}{l}\text { Cubic. } \\
\text { centi- } \\
\text { meters. }\end{array}$ & $\begin{array}{l}\text { Specific } \\
\text { gravity. }\end{array}$ & $\begin{array}{l}\text { Cubic } \\
\text { centi- } \\
\text { meters }\end{array}$ \\
\hline 0.8115 & 24 & 0.8095 & 18 & 0.8092 & 35 \\
\hline 0.8127 & 35 & 0.813 & 26 & Lost & 35 \\
\hline 0.8173 & 60 & 0.819 & 45 & 0.8195 & 60 \\
\hline 0.8185 & 22 & 0.8195 & 17 & 0.8213 & 25 \\
\hline 0.820 & 160 & 0.8215 & 130 & 0.8235 & 150 \\
\hline \multirow[t]{2}{*}{0.8215} & 310 & 0.824 & 340 & 0.826 & 280 \\
\hline & 611 & & 576 & & 585 \\
\hline
\end{tabular}

To see how much of the weight of the earth used the second time was due to material which it had retained from its first use, 300 grams of earth were mixed with $300 \mathrm{cc}$. of crude petroleum and the oil displayed by water. The oil recovered measured 205 cc., and the weight of the earth after drying for several weeks at room temperatures was 347.5 grams. Fully I5 per cent., therefore, of the weight of the earth used the second time was solid matter which it had retained from its first use.

While slow geologic processes may drive out most of the water, the evidence is in favor of the view that some of the oil will always be left behind. Some experimental work on samples collected in the field confirms the laboratory results:

The "cap rock" of oil accumulations in Caddo Parish, Louisiana, consists of a fine-grained clay of a 
considerable thickness. It has no odor of oil nor any oily feeling, in fact appears to be perfectly barren. By extracting with ether, however, a noticeable amount of petroleum is obtained of considerable greater viscosity than the petroleum supply below. The clay contains much moisture, and it is absolutely evident that it once contained more oil than at the present time. It seems, therefore, to be a case in point of where petroleum has accumulated by the capillary action of water. This seems to point out an extremely useful application of the phenomena described above.

To better compare the oils of different specific gravities that were obtained in the fourth fractionation each of six $300 \mathrm{cc}$. samples (five of partly refined oil and one of crude petroleum) was separated by distillation into ten fractions. Each sample was distilled in the same $500 \mathrm{cc}$. distilling bulb, which was heated by an electric stove that entirely surrounded it. The oil was first heated to $200^{\circ}$ under atmospheric pressure and then to $360^{\circ}$ under a pressure of $50 \mathrm{~mm}$. The diminished pressure was obtained with a large Chapman water pump and kept constant by the use of a valve which automatically admitted air to the evacuated system whenever the pressure fell below $50 \mathrm{~mm}$. This valve was constructed from a piece of iron pipe $I$ inch in diameter and 5 feet long. The lower end was closed with a cap and the pipe filled with mercury to a depth of $76 \mathrm{~cm}$. The upper end of the pipe was closed with a two-hole rubber stopper. In one hole was a long glass tube with the lower end beveled, which reached to the bottom of the mercury and could be raised or lowered as the barometer varied from day to day. In the other hole was a tube which passed just through the stopper and was connected on the outside with the apparatus to be exhausted. To prevent mercury from being drawn up and over into the apparatus by the air admitted, the end of the tube inside the stopper was drawn out and bent at a right angle and over this was slipped a cap made of larger tubing closed at the bottom, but having a fine opening in the side for air. This cap was about $6 \mathrm{~cm}$. long and extended about $3 \mathrm{~cm}$. below the end of the tube inside. If any mercury passed through this first fine opening into the cap, it would fall to the bottom without being drawn over into the apparatus or clogging the fine opening in the tube leading thereto. With this valve there was no difficulty in keeping a pressure of $50 \mathrm{~mm}$. constant within I $\mathrm{mm}$.
AND ENGINEERING CHEMISTRY. July, Igog

Each distillate of sufficient volume, which was not too viscous or partly solid, was tested as to specific gravity, viscosity, and percentage absorbed when treated with concentrated sulphuric acid (specific gravity 1.84).

Viscosity was measured by taking the time of flow of a measured volume of oil through a capillary, the viscometer used being the one described by Ostwald and Luther as modified by Jones and

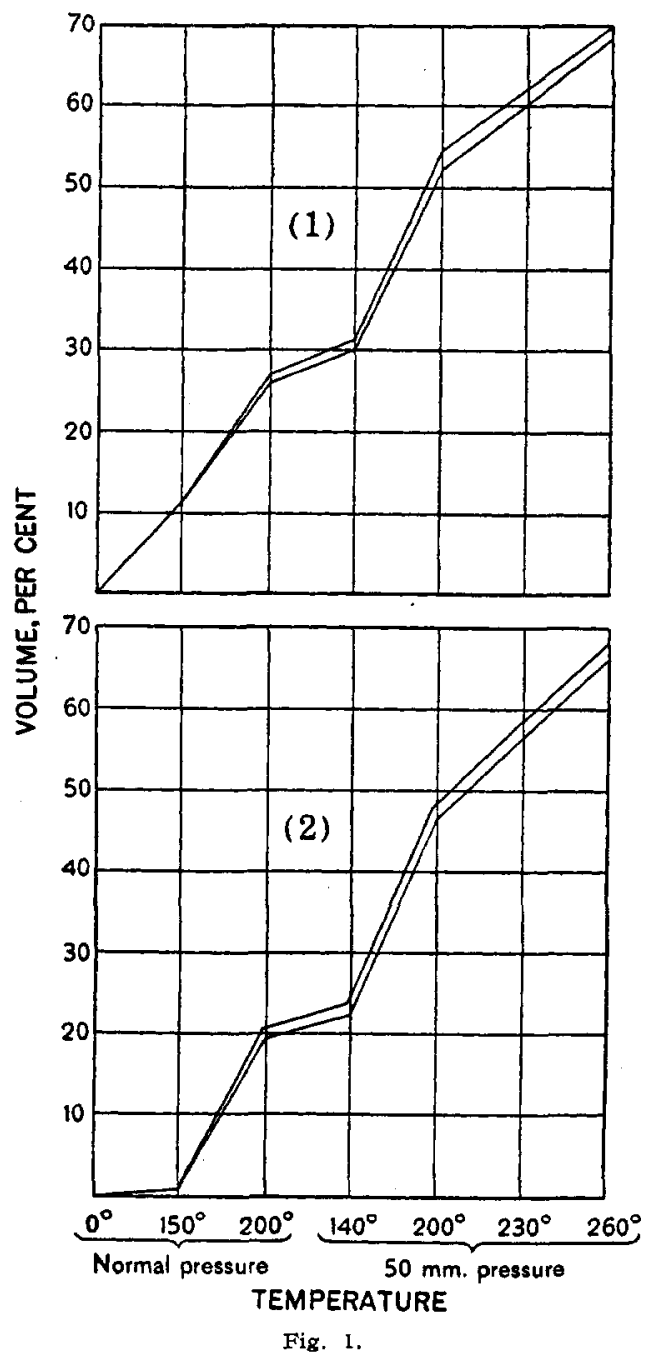

Veazey. ${ }^{1}$ The capacity of the small bulb was $4.5 \mathrm{cc}$. and the diameter of the capillary such as to require from five to eight minutes for that amount of oil to flow through it, and I minute 2.6 seconds for the same amount of water. The viscosity as well as the specific gravity was always measured at a temperature of $20^{\circ} \mathrm{C}$. Viscosities have been calculated from the formula $n=n_{0} \mathrm{TS} / \mathrm{T}_{0} \mathrm{~S}_{0}$

1 Ztschr. physik. Chemie, 61, 651. 
in which $n_{\circ}$ is the coefficient of viscosity for water, $S_{\circ}$ is the specific gravity of water, and $T_{0}$ the time of flow of water through any given capillary at a given temperature; $n$ is the viscosity coefficient of the solution investigated, $\mathrm{S}$ is its specific gravity as compared with water as unity at any given temperatures, and $T$ is the time of flow of the given solution at that temperature. The value acid were then poured into a separating funnel and the acid drawn off. The oil was then washed twice with water, once with aqueous $\mathrm{NaOH}$, again with water, and then with this last wash water poured into a burette and allowed to settle. After standing over-night the volume was read.

The oils boiling below $200^{\circ}$ (at $50 \mathrm{~mm}$. pressure) separated clear, but the heavy distillates were

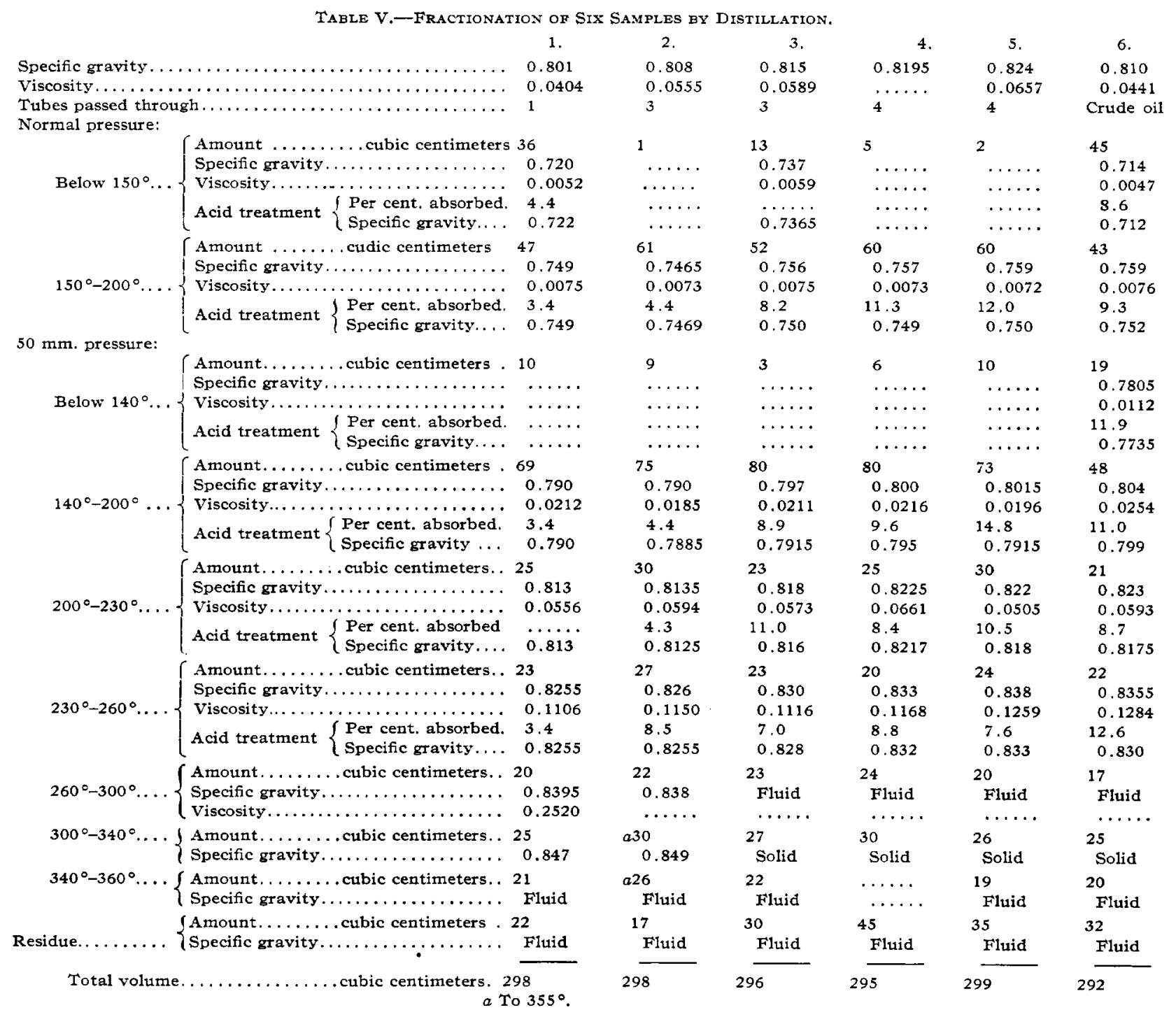

for pure water at $20^{\circ}$ was taken from the work of Thorpe and Rodger. ${ }^{1}$

Thirty cc. of each of these distillates where that much oil was available, or all the oil there was where the volume was less than $30 \mathrm{cc}$, were mixed with an equal volume of concentrated sulphuric acid (specific gravity 1.84 ) and shaken for half an hour or longer in a shaking machine. The oil and

1 Phil. Trans., Vol. 185 A, 1894, p. 397.

milky from water. The volume of these milky oils was read, their specific gravity was taken, and then the milkiness was removed by shaking and heating to about $60^{\circ}$ with $\mathrm{CaCl}_{2}$. The specific gravity of the clear oil was then taken and the proper correction made to the milky volume. In no case, however, was this correction large, and only for the three or four heaviest oils did it exceed one-half of I per cent., the largest correction of 
all being 2.6 per cent. for the distillate between $230^{\circ}$ and $260^{\circ}$ of the oil of specific gravity 0.824 . An attempt to treat with acid the oils selected to be distilled resulted in so much loss from the formation of emulsions that the loss in volume and change in specific gravity could not be determined with any degree of accuracy.

The results of the distillation of these samples are summarized in Table $\mathrm{V}$.

"Fluid" means that the oil at $20^{\circ}$ was partly solid, but would flow when the bottle was inclined; "solid" means that the oil would not change its shape when the bottle was turned upside down.

It was hoped that sulphuric acid of the strength used would dissolve only unsaturated hydrocarbons and leave untouched the paraffins and benzene. By long-continued shaking at ordinary temperatures, however, with acid of this strength benzene is dissolved, provided that the acid is in large excess. On being shaken for four hours Ioo $\mathrm{cc}$. of benzene were completely dissolved in $434 \mathrm{cc}$. of acid.

Three of the distillates which had been shaken with acid showed no action when treated with a mixture of equal parts of concentrated sulphuric acid and fuming nitric acid, whereas this nitrating mixture did act on distillates which had not been previously shaken with sulphuric acid. The action of the sulphuric acid, therefore, appears to have been complete.

The results of the acid treatment showed that over 90 per cent. of the oil used consisted of paraffin hydrocarbons, and that in the filtration through earth the paraffin hydrocarbons tended to collect at the top of the tube and the unsaturated hydrocarbons at the bottom.

The increasing amount dissolved by sulphuric acid in the heavier oils may be seen in the curves shown in Figs. I to 3 . The abscissas represent temperatures and the ordinates volumes. The same distance on the $x$ axis is taken to represent a distillate, whatever be the number of degrees over which it may have been collected. The upper curve represents the percentage of the total volume that distilled between given temperatures; the lower curve the percentage of the total volume recovered that was not absorbed by sulphuric acid (that is, the paraffin hydrocarbons). For the upper curve the ordinates are obtained by dividing the number of cubic centimeters in the distillate by the total volume of oil recovered. For the lower curve the ordinates are obtained by dividing the number of cubic centimeters in the distillate not absorbed by sulphuric acid by the total volume of oil recovered.

The area between the two curves represents the proportion of hydrocarbons soluble in sulphuric acid. It will be seen that this is greatest for the oils of highest specific gravity.

The nature of the selective action in the diffusion of oils through clays seems to be complicated.

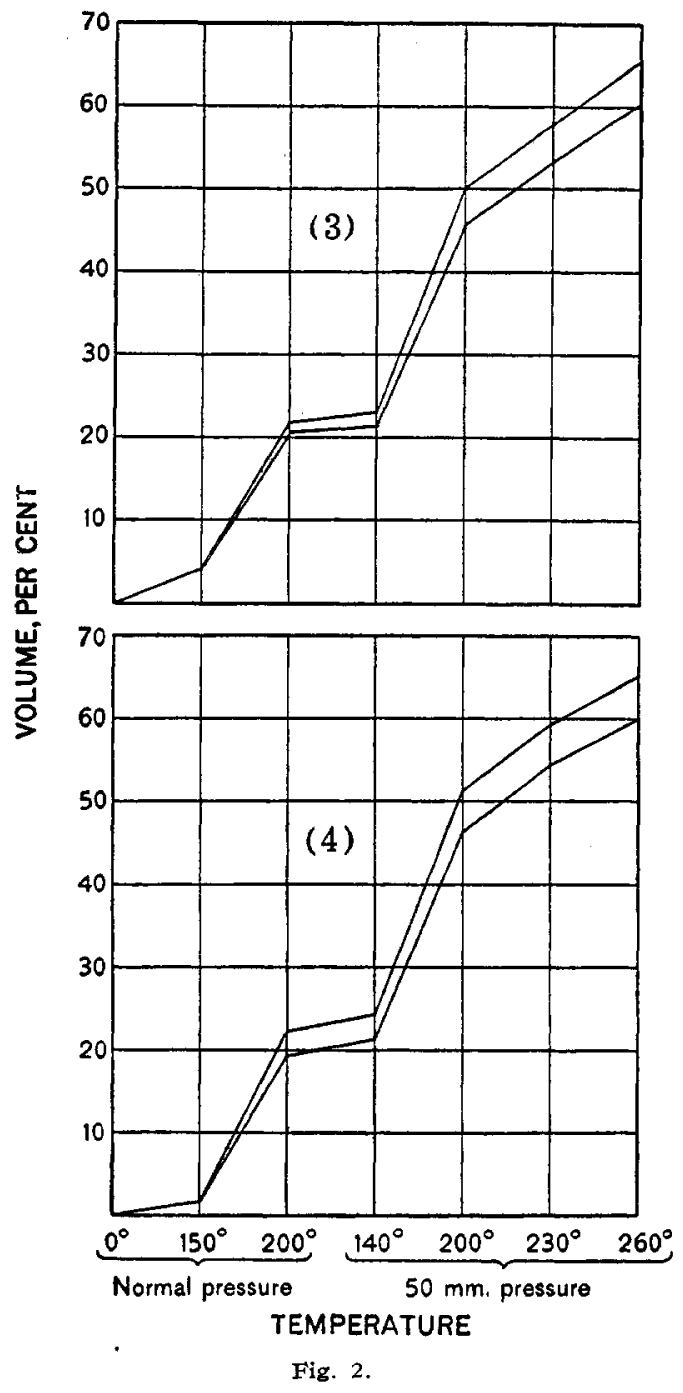

It is noticed that certain constituents of petroleum are held back with great readiness by the clay.

Such substances are, in the first place, asphalt and the sulphur compounds found in Texas petroleum. On the other hand, semi-solid paraffin is found in oils which have diffused so far through the clay as to be appreciably lighter in specific gravity. Again, it has already been shown that unsaturated hydrocarbons have a tendency to hang, that is, not to diffuse so readily as saturated hydrocarbons. 
Careful study of these phenomena leads to the suggestion, as a basis for future work, that the substances in colloidal suspension rather than those in more perfect solution are the first to be held back.

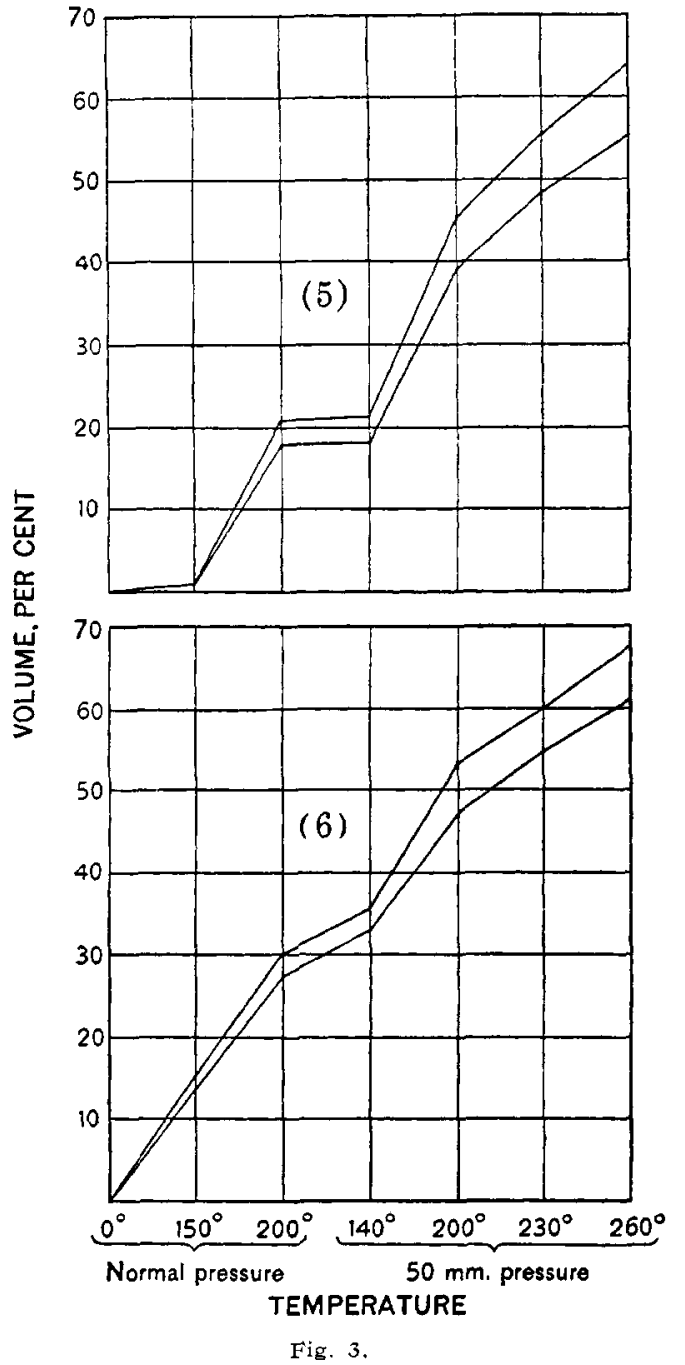

That this is particularly the case with asphaltic materials appears evident by the partially successful results already obtained by one of us, of precipitat$\mathrm{ng}$ asphalt from its suspension in petroleum by the presence of an electrolyte.

\section{FURTHER REMARKS ON VANADIUM AND ITS ESTIMATION. \\ By George Auchy. \\ Received March 16, 1909.}

An important question to the steel maker who must produce steel that will stand shock and alternating stresses is, whether or not, the earnest claim that vanadium is the best element to use to produce these qualities is a true one. Can vanadium do anything for steel that can not be done by nickel, chromium, tungsten, molybdenum, manganese, or silicon and does it outclass all these other elements in value and usefulness? The writer has made a search through the literature of the subject for an answer to this question, and while he has found an abundance of affirmative assertion, the evidence itself has been somewhat meager and contradictory evidence, that is, that bears directly on this question. Of evidence that vanadium does impart very valuable properties to steel there is no lack, and this elementary point, especially through the labors of Mr. J. Kent Smith, has received ample and complete demonstration. We need no longer ask whether vanadium is a good thing, but that it is the best thing as is so earnestly claimed, is not so clear, and as we have stated, it is to the steel maker, an interesting and important question. The writer wishes here to bring together results bearing on this point that have been quoted by him in several scattered numbers of the Iron Age (adding to them a few others), but expressing these results in single "quality figures" instead of in the original detailed tensile, shock, and hardness statements. These quality figures (the tensile, shock and hardness figures summed up and expressed in a single figure) were suggested to the writer by similar ones made use of by Mr. W. L. Turner in an able article in the Iron Age for July 2, 1908. But Mr. Turner's quality figures aim to combine only the static and dynamic properties of steel in a single figure, leaving out (perhaps properly) the hardness. Although he can not be severely (perhaps not at all) criticized for this omission, yet the general principle of his method of calculating the quality figure is obviously illogical, and his quality figures therefore are somewhat misleading. Upon reflection, it will be clear to every one that the following rule will give just results. Instead of multiplying the factors (in his method, elasticity, reduction, and alternate stress) together, as does Mr. Turner, we compare each factor separately with the same factor in some steel which we select for a standard, making the factor of the sample steel the numerator and the factor of the standard steel the denominator of a fraction. Both terms of the fraction are then divided by the least term either numerator or denominator as the case may be. Finally, after the common divisions the sum of all the numerators is 